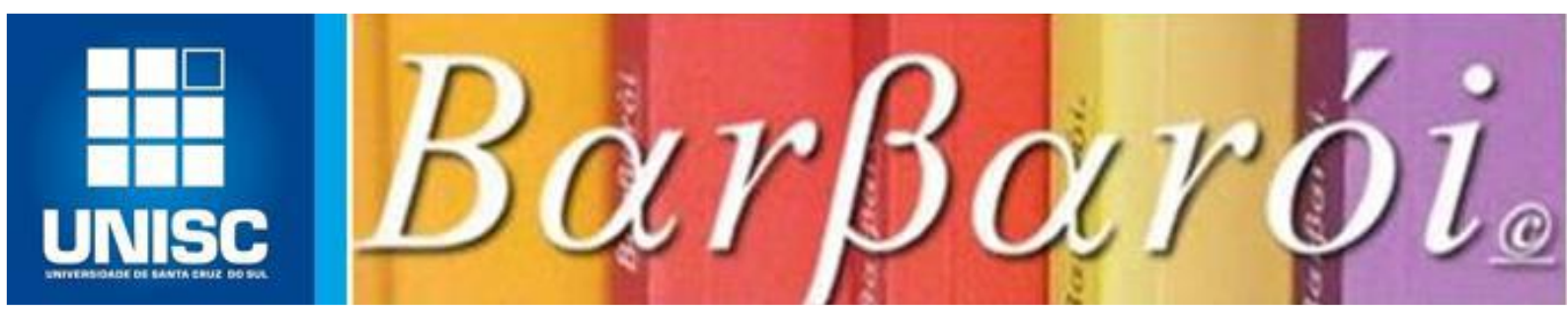

\title{
ESCOLA COMO UM ESPAÇO DE PREVENÇÃO DA VIOLÊNCIA: UM RELATO DE EXPERIÊNCIA
}

\author{
DOI: http://dx.doi.org/10.17058/barbaroi.v0i57.11266 \\ $*$ \\ Suane Pastoriza Faraj \\ Universidade Federal de Santa Maria - UFSM - Brasil \\ Juliano Beck Scott \\ Universidade Federal do Rio Grande do Norte - UFRN - Brasil \\ Aline Cardoso Siqueira \\ Universidade Federal Santa Maria - UFSM - Brasil
}

\section{Resumo}

Este trabalho objetivou relatar a experiência de oficinas de prevenção à violência realizadas com mães e responsáveis dos alunos matriculados em séries iniciais de duas escolas de um município do Rio Grande do Sul, no ano de 2013 e 2014. As oficinas tiveram o intuito de possibilitar um espaço de diálogo sobre a violência contra crianças e adolescentes a fim de preveni-la. As participantes relataram vivência de violência física em suas histórias de vida e no seu cotidiano, não possuindo recursos diferentes da punição física no disciplinamento. Foi relatada a presença do abuso do álcool nas famílias e o desconhecimento das leis de proteção à população infanto-juvenil. Os encontros se constituíram em um momento reflexivo sobre a violência e os danos da mesma no desenvolvimento dos sujeitos. Espaços como esse devem ser fomentados visando ao cumprimento do papel social da escola e da universidade como coadjuvantes na prevenção à violência.

Palavras-chave: Violência; prevenção; criança.

\section{Introdução}

A violência contra a população infanto-juvenil representa um problema de saúde pública e uma violação de direitos estabelecidos no Estatuto da Criança e do Adolescente ECA (BRASIL, 1990. Nesse sentido, diversas ações vêm sendo pensadas e instituídas como forma de evitar o fenômeno, entre elas a publicação de legislações, como a Lei $\mathrm{n}^{\circ}$ 13.010, conhecida como a Lei da Palmada (Brasil, 2014). 
Estudos científicos evidenciaram que a violência se manifesta, especialmente, através da negligência, agressões físicas, psicológicas e sexuais. Também mostraram que maioria dos casos de violência acontece na residência da criança e os pais são os principais agressores. Os dados apontaram que essa prática vem causando danos na saúde e bem-estar das crianças (CEZAR; ARPINI, 2017; FERREIRA; CÔRTES; GONTIJO, 2019; MALTA et al., 2017).

A violência contra as crianças e os adolescentes no âmbito da família pode ser compreendida como toda prática realizada por pais e/ou familiares que resulta em danos à criança e ao adolescente. Trata-se de um fenômeno complexo de caráter multicausal, no qual envolve a interação simultânea de fatores biológicos, individuais, familiares, culturais e comunitários. O estresse familiar, problema de comunicação na família, práticas disciplinares punitivas, poucas habilidades parentais, isolamento social, alcoolismo e uso de drogas, estão entre os fatores que podem estar implicados na violência contra a criança e o adolescente (KRUG et al., 2012). É importante considerar que, fatores como a pobreza, o desemprego, as más condições de vida e de sobrevivência, a carência do acesso às políticas públicas contribui para a vulnerabilidade social das famílias e, portanto, para a desproteção das crianças e dos adolescentes, bem como situações de violação de direitos (PEDERSEN; GROSSI, 2011). Neste sentido, para enfrentar o fenômeno se faz necessário, muito mais do que a implantação de legislações na área jurídica, é importante implementar ações de prevenção, na qual envolve toda a rede de proteção, visto que esta é constituída por diversas instituições, dentre elas, as escolas.

As instituições escolares têm o compromisso social de assegurar os diretos das crianças e adolescentes estabelecidos no ECA e prevenir as formas de violação de direitos contra esta população, dentre elas, a violência. Dessa forma, algumas iniciativas vêm sendo realizadas no Brasil na área da educação para prevenir a violência contra a criança e o adolescente. Como exemplo, pode-se citar o "Projeto Escola que Protege", desenvolvido pelo Ministério da Educação por intermédio da Secretaria de Educação Continuada, Alfabetização e Diversidade (Secad), no ano de 2004. Este projeto visou à promoção de ações educativas e preventivas nas escolas a fim de enfrentar à violência (FALEIROS; FALEIROS, 2008).

O papel da escola e dos profissionais que atuam neste espaço no enfrentamento da violência contra a criança e o adolescente é discutido e reconhecido na literatura científica (FALEIROS; FALEIROS, 2008; LYRA; CONSTANTINO; FERREIRA, 2010; RISTUM, 2010). A escola é referenciada como um local em que é possível identificar as situações de violência envolvendo as crianças e adolescentes, escutar e acolher as famílias, atuar de 
maneira interdisciplinar diante do fenômeno e construir estratégias de prevenção da violência (LYRA, CONSTANTINO, \& FERREIRA, 2010; RISTUM, 2010). É importante considerar que a escola sofre com as implicações da violência familiar, podendo ser um local de reprodução do fenômeno.

A Organização Mundial da Saúde (OMS) reconhece a prevenção como a forma mais efetiva para enfrentar a violência no âmbito familiar, sugerindo três modalidades: primária, secundária e terciária. A prevenção primária é dirigida à população em geral, atingindo um maior número de pessoas de diferentes grupos sociais e culturais. Esta modalidade, em geral, objetiva a conscientização da população a cerca da problemática da violência, de promoção de atitudes adequadas no cuidado dos filhos, de orientação às famílias em situação de vulnerabilidade, com o desígnio de eliminar ou reduzir os fatores sociais, culturais e ambientais que propiciam a ocorrência de situações de violência. As ações de prevenção primária são baseadas em divulgações de grande alcance, como campanhas em televisão, jornais, pôsteres. Também está incluída na implementação de práticas políticas atuantes em uma comunidade, ou seja, desenvolvimento de estratégias e programas que visem à promoção de saúde (HUTZ, 2002; IPOLLITO, 2004). A secundária é dirigida especialmente aos grupos mais vulneráveis e em situação de risco de ocorrência de violência, tais como: dependência de droga, presença de doença crônica ou necessidades especiais na família, pobreza, desemprego, situação de moradia ou condições de saúde inadequadas. As técnicas preventivas se baseiam na promoção de atividades de apoio e educativas dirigidas diretamente aos grupos de risco, visando à integração dos membros da comunidade e a criação de redes sociais para o desenvolvimento de atividade com crianças e adolescentes (HUTZ, 2002). A prevenção terciária, por sua vez, se dirige a família em que foram identificadas situações de violência e necessitam de um trabalho especializado de atendimento. Tem como objetivo interromper o ciclo da violência, através da identificação de formas de prevenir a recorrência de novos episódios e de atender a crianças e adolescentes em suas necessidades decorrentes das consequências advindas da violência (HUTZ, 2002).

O Relatório Mundial de Saúde e Violência (KRUG et al., 2002) apontou que para atuar em situações de violência é indispensável algumas ações, entre elas: intervir nos fatores individuais de risco; promover relações interpessoais afetivas e atuar para desenvolver ambientes familiares saudáveis, assim como disponibilizar o apoio às famílias que apresentam fatores de risco; enfrentar os fatores culturais, sociais e econômicos que colaboram para a ocorrência da violência, e implementar medidas para modificar esses fatores. A escola, a 
partir da sensibilização a respeito da gravidade da violência e das consequências provindas desse fenômeno para o desenvolvimento infantil pode promover ações de prevenção da violência em prol da saúde e desenvolvimento das crianças e dos adolescentes (GARBIN et al., 2015). Instituições que estimulam a presença e participação de pais e responsáveis e que promovam o diálogo com a família, conseguem com mais êxito ajudar as famílias que adotam a violência como forma de resolução de problemas (LYRA; CONSTANTINO; FERREIRA, 2010). No entanto a escola, não pode enfrentar o fenômeno sozinha, dessa forma precisa contar com o apoio de órgãos como Conselho Tutelar, Delegacia de Proteção a Criança e o Adolescente, Ministério Público; e também Políticas Públicas da Assistência Social e da Saúde.

Considerando a prevenção primária como uma forma de reduzir a violência contra a população infanto-juvenil e pensando na escola como o local onde é possível realizar intervenções preventivas, este trabalho apresenta um relato de experiência de ações realizadas por meio do Projeto de extensão "Violência contra crianças e adolescentes: trabalhando prevenção primária". Além disso, visa refletir teoricamente sobre alguns temas que se destacaram nas oficinas e que são fatores importantes para o enfrentamento da violência.

\section{Procedimentos metodológicos}

O projeto de extensão "Violência contra crianças e adolescentes: trabalhando prevenção primária" foi desenvolvido, durante os anos de 2013 e 2014, em duas escolas localizadas em uma cidade do interior do Rio Grande do Sul. Uma das escolas se refere a uma instituição pública municipal localizada na região oeste do município. A outra instituição também está localizada na região oeste, no entanto, é uma instituição filantrópica mantida por uma entidade religiosa. Ambas as instituições são de ensino fundamental e atendem crianças e adolescentes em situação de vulnerabilidade social.

O projeto teve o intuito de responder à demanda identificada a partir da supervisão de estágios acadêmicos em um Centro de Referência Especializado da Assistência Social (CREAS) do Município, no qual ofertava atendimento psicossocial à criança, adolescente e família em situação de violência. Assim, na supervisão do estágio acadêmico, identificou-se a necessidade da oferta de ações para a redução de casos de violação de direitos na região oeste, o qual apresentava muitos casos de violência, conforme, identificado no CREAS, somado ao quadro de pobreza, vulnerabilidade social, desemprego e tráfico de drogas. 
O projeto teve como objetivo prevenir que pais e/ou responsáveis utilizem a violência como forma de interação com seus filhos. Dessa forma, ofertou um espaço de diálogo às mães, pais e responsáveis pelas crianças e adolescentes, no qual eles pudessem discutir e refletir acerca de temas como desenvolvimento infantil, práticas educativas, drogas, dentre outros.

A ação teve início no ano de 2013 na escola municipal, e no ano seguinte na instituição filantrópica. Em ambas as instituições, primeiramente ocorreram à inserção nos locais e o convite aos pais e responsáveis dos alunos para participar dos encontros. Os encontros aconteceram nas dependências das escolas, de frequência semanal, com dias previamente determinados e com duração de aproximadamente uma hora e trinta minutos. $\mathrm{Na}$ primeira instituição, os encontros ocorreram no período de agosto a novembro do ano de 2013. Na segunda escola os encontros ocorreram no período de abril a agosto de 2014.

Em ambas as instituições, foram realizados onze encontros, no decorrer do ano. Estes tiveram como temas norteadores, dentre outros, o desenvolvimento infantil, os danos da violência no desenvolvimento, práticas educativas positivas, direitos da população infantojuvenil, rede de proteção à criança e ao adolescente, prejuízos do álcool e outras drogas. Nas oficinas, como forma de possibilitar a expressão dos sentimentos e o diálogo sobre a temática, foram utilizados materiais lúdicos, audiovisuais e informativos, como vídeos e cartilhas a respeito dos temas norteadores.

Quanto às participantes, na escola municipal somavam um total de dez e na escola filantrópica, um total de sete. Estas eram mães/responsáveis de alunos matriculados nas séries iniciais das respectivas escolas. As participantes tinham entre 26 e 60 anos de idade, a maioria era casada e não trabalhava fora de casa. No decorrer do ano, permaneceram apenas três mães de ambas as instituições. Pensa-se que este fato pode estar relacionado a alguns fatores, dentre eles, a dificuldade de falar sobre o assunto, assim como o fragilizado vínculo das participantes com a instituição escolar que estava apoiando as oficinas, visto que a instituição escolar serviu de suporte para realização das oficinas junto à comunidade.

As crianças das séries iniciais foram escolhidas justamente devido à prevenção primária buscar a conscientização da violência e de se trabalhar essas questões desde a segunda infância, tempo em que a criança se insere nas instituições escolares participantes do estudo. Trabalhar com a conscientização de mães e responsáveis, desde cedo, auxilia na prevenção da violência. 
As oficinas foram desenvolvidas por uma equipe de cinco pessoas composta por uma acadêmica do Curso de Psicologia da Universidade Federal de Santa Maria (UFSM), dois mestrandos do Programa de Pós-Graduação em Psicologia da UFSM e uma psicóloga, sob a orientação de uma docente do Departamento de Psicologia e do Programa de Pós-Graduação em Psicologia da UFSM. Após a realização dos encontros, anotações em um diário de campo foram realizadas minuciosamente, pelos coordenadores das oficinas, na qual foram utilizadas para esse relato de experiência. Assim, quatro temáticas relacionadas à prevenção e ao enfrentamento da violência se fizeram presentes de maneira mais significativa nos encontros e serão discutidas: (1) Alternativas à punição física, (2) Álcool e outras drogas como fatores de risco para a violência, (3) Práticas parentais e os danos da violência conjugal e intrafamiliar e (4) A Rede de proteção à criança e ao adolescente na prevenção e enfrentamento da violência.

\section{Resultados e discussão}

Alternativas à punição física

As diferentes maneiras de educar os filhos em idade escolar foram expostas e compartilhadas nas oficinas. Algumas mães apontaram "o diálogo" como uma prática utilizada na educação com os filhos, no entanto, a maioria assinalou que utilizavam a punição física como forma de educar e lidar com o comportamento indesejado do filho (gritos, desobediência, agressão física, etc.). Uma das participantes expôs como age no seu dia a dia em relação aos seus três netos, relatando que os ajuda nas tarefas de casa, paga uma pessoa para ficar com os mesmos quando tem que sair, não deixa as crianças brincarem sozinhas na rua, no entanto, verbalizou que utiliza da força física para educá-los. A literatura científica vem evidenciando que pais e cuidadores utilizam tanto práticas positivas, como o diálogo, quanto negativas na educação dos filhos, como a punição física (ALTAFIM; RODRIGUES, 2015; ALTSCHUL; LEE; GERSHOFF, 2016). De acordo com Cecconello, De Antoni e Koller (2003), apesar das mudanças nas relações intrafamiliares relacionadas à utilização de força física como uma forma de educar as crianças por parte dos pais/cuidadores, ainda prossegue a punição física no contexto familiar sendo justificada, na maioria das vezes, como uma prática educativa. O limite entre punição física e violência física é muito tênue, sendo uma questão de intensidade.

A violência física se refere ao uso da força física de forma intencional que pode causar danos à criança e/ou adolescente. Pode ser praticada através de beliscões, tapas, chutes, sufocamentos (BRASIL, 2010). Dessa forma, pode ser de fácil diagnóstico, pois deixa marcas 
visíveis, podendo ser identificada por meio de lesões orgânicas (cutânea, óssea, oculares e neurológicas) e físicas como hematomas e/ou queimaduras em estágios diversos de cicatrização (DE ANTONI; KOLLER, 2010; IPPOLITO, 2004). As crianças que vivenciam uma situação de violência física podem apresentar humor deprimido, comportamento agressivo e terem dificuldade de aprendizagem (MONTEIRO et al., 2018). Nos encontros, pode-se perceber que a violência física, muitas vezes, foi justificada como uma tentativa de disciplinar, educar, colocar limites e ensinar, não sendo lembrada, na maioria das vezes, que essa ação pode estar relacionada a problemas de saúde mental na infância e adolescência (SÁ et al., 2010).

De acordo com o estudo de De Antoni e Koller (2012), o autoritarismo, o descontrole emocional, a falta de confiança e a exigência para com os filhos são algumas características observadas nos cuidadores que agridem fisicamente as crianças e os adolescentes. A partir do relato das participantes, pode-se perceber que a forma de agir com os filhos/netos estava relacionada a estes fatores, mas também as formas como elas foram educadas. As participantes recordaram suas histórias pessoais e vivências de violência física como forma de educação e disciplina. Esse contexto sugere que, para elas, educar é usar punição física, não existindo outras formas de disciplinar que não essa.

A partir da exposição dos coordenadores das oficinas a respeito da diferença entre as práticas educativas positivas e negativas, as participantes puderam refletir sobre seus comportamentos. Além disso, a discussão possibilitou que as participantes apontassem como práticas alternativas à punição física a participação nas atividades das crianças, o diálogo, o discurso coerente com os filhos, o estabelecimento de regras e acordos. É importante salientar que as práticas educativas positivas envolvem o uso adequado de atenção, estabelecimento de regras, a supervisão das atividades escolares e lazer, entre outras. Entretanto, as práticas educativas negativas estão relacionadas ao abuso físico e psicológico, ausência de atenção e afeto, monitoria negativa, disciplina relaxada e punição inconsciente (GOMIDE, 2006).

No âmbito da discussão acerca da temática da violência física, a "Lei da Palmada" foi abordada pelas participantes. A Lei n. 13.010 (brasil, 2014) alterou o Estatuto da Criança e do Adolescente para constituir o direito da criança e do adolescente de serem educados e cuidados sem o uso de castigos físicos ou de tratamento cruel ou degradante. Na reflexão envolvendo o assunto, foi unânime entre as participantes a aceitação e concordância a respeito do objetivo da referida legislação. As mães e responsáveis que participaram da oficina acreditavam que muitos pais não conseguem ter controle sobre a força e acabam excedendo 
na punição física, neste sentido a Lei pode prevenir a violência física contra a população infanto-juvenil. Para Pellegrini, Paiva, Feltrin e Feversani (2013), as consequências do uso ou não da palmada no desenvolvimento dos sujeitos e na sociedade devem ser refletidas. Os autores consideram que não há uma receita para educar e corrigir o comportamento considerado errado do filho, devendo existir a ponderação das práticas utilizadas, mas sempre preconizando a integridade física e psíquica da criança/adolescente.

\section{Álcool e outras drogas como fatores de risco para a violência}

De acordo com a OMS, aproximadamente $10 \%$ da população urbana mundial utiliza, de forma abusiva, algum tipo de substância psicoativa. Isso faz com que muitos se tornem dependentes químicos, devido ao uso compulsivo da substância, priorizando o seu consumo em detrimento dos danos (BRASIL, 2004).

Oliveira, Bittencourt e Carmo (2008) chamam atenção para dados ainda mais alarmantes. Segundo os autores, houve no Brasil, a partir de 1987, um aumento significativo no consumo de substâncias psicoativas entre crianças e adolescentes. Esse aumento, principalmente entre os jovens, configura-se como problema de saúde pública, pois afeta o indivíduo, sua família e comunidade. Esses dados corroboram com Brasil (2004, p. 5), ao afirmar que o uso abusivo ocorre "independente de idade, sexo, nível de instrução e poder aquisitivo", o que demonstra que, tanto o risco como as conseqüências da utilização do álcool e/ou outras drogas, podem afetar qualquer parcela da população.

O uso de álcool e/ou outras drogas, portanto, tem sido considerado uma questão de saúde pública para vários países, dentre eles o Brasil. Nesse sentido, foi aprovada no ano de 2019, por meio do decreto $\mathrm{n}^{\circ}$ 9.761, de 11 de abril de 2019, a Política Nacional sobre drogas (Pnad) com vigência em todo território nacional. Conforme o anexo da resolução, a Pnad foi criada com o intuito de garantir a assistência aos usuários de forma holística e interligada aos vários serviços disponíveis, por meio de ações, programas e atividades de atenção, cuidado, assistência, prevenção e tratamento, bem como reinserção social.

As oficinas abordaram a questão do álcool e/ou outras drogas de forma informativa, por meio da utilização de uma cartilha sobre a rede de atendimento à população vulnerável da cidade, assim como vídeos e discussões sobre substâncias psicoativas. Conforme Henriques, Rocha e Reinaldo (2016), que realizaram uma revisão integrativa sobre o uso de crack e outras drogas por crianças e adolescentes e sua relação com a família, a proteção da família é 
um fator importante na prevenção do uso de drogas, afastando os jovens do consumo quando da presença de uma família protetora que compartilha sentimentos de cumplicidade e respeito.

Pensando nisso, buscou-se instrumentalizar as participantes das oficinas, visto que apontaram o álcool e/ou outras drogas como fatores presentes na comunidade e na família. O álcool, por exemplo, apareceu como agravante negativo das relações conjugais, pois, segundo os relatos, seus companheiros se tornam agressivos sob uso da droga, violentando-as (participante da oficina) e/ou os filhos.

Conforme Vieira et al. (2014), o uso abusivo de álcool e outras drogas afeta as relações conjugais, principalmente as mulheres, que se tornam vítimas de seus companheiros alcoolistas. Ou seja, o álcool pode contribuir para relações lesivas, pois, conforme Zilberman e Blume (2005), o álcool pode atuar como desinibidor, facilitando casos de agressões e de violência.

Schenker e Minayo (2005) atentam para o fato de que o uso do álcool e/ou outras drogas pode estar ligado ao risco e/ou fatores de risco a que estão expostos os sujeitos. Para as autoras, o risco envolve a exposição a determinadas situações com o objetivo de realizar um desejo. Entretanto, tal situação, pode incluir além da possibilidade de ferimentos físicos e outros agravos, consequências psicológicas. Os fatores de risco, por sua vez, envolvem toda ação que provoque resultados negativos para a saúde, bem-estar ou prática social do sujeito, tornando-o vulnerável.

Oliveira, Bittencourt e Carmo (2008, p. 4) ressaltam que, dentre os fatores de risco para uso e abuso de álcool e/ou outras drogas, estão as "precárias condições de moradia, presença do tráfico, ausência de perspectivas de trabalho, de ascensão social e de opções de vida socialmente integradoras". Além disso, conforme salienta Silveira e Silva (2013), também existem fatores de risco presentes no ambiente familiar, como vínculos familiares precários, pais demasiadamente autoritários ou até mesmo permissivos com relação ao uso e consumo de drogas. De acordo com Barros e Tucci (2018), esses fatores podem ser preditores do uso e abuso de drogas, visto que crianças e adolescentes que presenciam a prática do uso de drogas, podem reproduzir esse tipo de comportamento por compreendê-lo como um modelo que pode ser seguido.

Percebeu-se pelo relato das participantes uma preocupação quanto à influência negativa que o companheiro alcoolista provocava no(s) filho(s). Segundo as mães/responsáveis, o comportamento do companheiro alcoolista parece influenciar 
negativamente o comportamento dos filhos, que acabam por reproduzir em suas relações a forma agressiva observada.

Conforme Schenker e Minayo (2005), o alcoolismo possui uma influência negativa no funcionamento familiar, inclusive influenciando os comportamentos entre os membros familiares devido à transmissão intergeracional. As autoras ressaltam que o comportamento parental serve de modelo para os filhos. Portanto, se os pais possuem um tipo de atitude permissiva, essa atitude pode influenciar os filhos na repetição de comportamentos ditos negativos, como o uso do álcool, por exemplo.

Segundo Minayo e Deslandes (1998), apesar das evidências empíricas de que o álcool aparece articulado com várias formas de violência, este ainda possui o status de legalidade que lhe permite a comercialização e a venda, sendo, inclusive, socialmente aceito e consumido. Fato ainda mais agravante se deve ao fato, conforme Brasil (2004), do uso do álcool impor a sociedade agravos indesejáveis e dispendiosos, devido aos problemas decorrentes do seu consumo e a necessidade de respostas políticas para seu enfrentamento.

Nos encontros, as participantes ressaltaram a facilidade do acesso ao álcool e outras drogas, principalmente o crack, na sua comunidade de entorno. De acordo com Reis, Uchimura e Oliveira (2013), o uso de drogas de abuso, dentre elas o crack, tem crescido desde a década de 1990. Os referidos autores ressaltam que o problema do uso de drogas aparece, com maior frequência, nas comunidades ditas vulneráveis, devido aos problemas sociais constantes, problemas econômicos e de saúde pública, que envolvem tanto a dificuldade de acesso aos bens e serviços, como a violência e a criminalidade presente nesses locais. Segundo os autores, todos esses fatores contribuem para o acesso e o consumo da droga. Portanto, discussões sobre esse assunto são de relevante importância para auxiliar na prevenção da violência devido ao uso e abuso de substâncias psicoativas, principalmente em locais de vulnerabilidade, como o local/comunidade de residência das participantes.

\section{Práticas parentais e os danos da violência conjugal e intrafamiliar}

A violência vivenciada no âmbito familiar manifestada através de agressões, violência física e psicológica, por parte do companheiro, foi apontada pela maioria das participantes das oficinas. O relato delas acerca da violência se assemelha bastante ao discurso presente na ordem patriarcal vigente em muitas das famílias brasileiras.

De acordo com Narvaz e Koller (2006), o patriarcado se constitui em uma forma de organização social em que prevalece a supremacia masculina, ou seja, na sociedade patriarcal 
a mulher está subordinada ao homem. De acordo com D'Incao (2015), esse tipo de organização social e doméstica, centralizada no poder dos homens, prejudica as mulheres devido à desigualdade e hierarquia existente entre os gêneros, podendo, inclusive, gerar situações de abuso e violência para outros familiares.

As participantes, em sua maioria, trouxeram aspectos peculiares ao modelo patriarcal, pois cuidam dos afazeres domésticos e do cuidado com os filhos, não tendo autonomia frente ao companheiro, que dita as regras e busca o sustento da família, aparecendo como principal ou único provedor financeiro. Esse aspecto reforça o poder de autoridade do homem dentro do lar, provocando desigualdade nas relações de poder entre homens e mulheres, prejudicando a relação conjugal e familiar (NARVAZ; KOLLER, 2006).

Conforme Scott e Cezne (2012), no modelo de família patriarcal, prevalecem regras muito rígidas e papéis de homem e mulher bem definidos. Isso pode contribuir para que ocorram disparidades e assimetrias nas relações de poder dentro da família. No caso de famílias pauperizadas, a condição socioeconômica pode repercutir em maiores dificuldades de sobrevivência, além de episódios de abandono, negligência e/ou violência (KOLLER; DE ANTONI; CARPENA, 2012).

Oliveira e Gomes (2011) ressaltam que a violência conjugal ganhou maior notoriedade a partir dos movimentos feministas principalmente devido às denúncias contra o poder patriarcal e seus efeitos opressivos sobre as mulheres. Essas práticas opressivas e violentas, de acordo com Jaeger (2013), advém da utilização injusta e abusiva de poder, podendo se expressar das mais diversificadas formas, como, por exemplo, através da violência de gênero, muito comum e presente em relações dominadoras e opressivas.

Segundo Silveira, Nardi e Spindler (2014), a violência de gênero permaneceu intacta por muito tempo na sociedade, principalmente naturalizada através da dominação masculina. Segundo os autores, o movimento feminista contribuiu para denunciar a violência de gênero como parte da dimensão pública, social e coletiva que deve ser evitada. A partir do momento em que a violência de gênero começou a ser discutida, buscou-se uma maior igualdade entre os gêneros, inclusive, como parte dos direitos humanos (SILVEIRA; NARDI; SPINDLER, 2014).

Nos encontros, observou-se que a maioria das participantes já haviam sofrido violência de gênero, principalmente a violência doméstica, expressa por meio da submissão e subordinação ao companheiro, assim como através de situações de violência física, psicológica e/ou sexual. Conforme D’Affonseca e Williams (2011), estudos têm indicado que 
a violência de gênero extrapola a relação conjugal afetando os filhos. As autoras ressaltam que várias pesquisas têm apontado a violência contra o parceiro como fator de risco para a violência contra a criança.

D’Affonseca e Williams (2011, p. 238) defendem que "a mãe que vivencia agressões físicas e psicológicas do parceiro muitas vezes não está em condições de estabelecer um relacionamento adequado com os filhos", o que pode comprometer a qualidade da sua maternagem. Saffioti $(1999 ; 2004 ; 2013)$ destaca que na violência de gênero prevalecem agressões do homem contra a mulher fomentada principalmente pela relação desigual de poder criada no ambiente familiar. Essa relação desigual tende a afetar os filhos, fazendo com que muitas mulheres maltratem-os devido à hierarquia inferior por eles ocupada na esfera familiar. Isso é expressão de uma síndrome denominada "Síndrome do pequeno poder" em que tanto homens como mulheres podem se tornar agressores. A "Síndrome do pequeno poder" pode ocorrer em espaços onde o agressor se utiliza da opressão para compensar a sensação de impotência a que está submetido em outros tipos de contextos ou relações (SAFFIOTI, 1999).

Os encontros possibilitaram a identificação desse tipo de síndrome também em outras relações de parentesco expressas pelas participantes, como, por exemplo, no caso de uma avó que tem a guarda de dois de seus netos. A violência que essa participante sofre do companheiro parece repercutir no modo como trata os netos, assim como a bisavó dos mesmos. Portanto, a "síndrome do pequeno poder" pode surgir em qualquer grau de parentesco, pois, conforme Saffioti $(1999 ; 2004)$ a mulher, na hierarquia doméstica, pode vir a exercer uma espécie de tirania contra as crianças devido a assimetrias de poder presentes no contexto familiar.

Conforme estudo de Sani e Cunha (2011), a violência conjugal, além de comprometer a prática parental das mulheres, interfere na sua saúde e no seu reconhecimento como mulher e progenitora. Isso quer dizer que mulheres que são vítimas de violência tendem a punir mais os filhos por meio de práticas disciplinares coercitivas. Essas mulheres também sofrem mais com baixa autoestima, depressão e ansiedade e apresentam maior insegurança no cuidado e vinculação com os filhos (SANI; CUNHA, 2011; JUSTINO; COTONHOTO; NASCIMENTO, 2017).

Segundo Reichenheim, Dias e Moraes (2006), mostra-se necessário um suporte através do atendimento nas redes básicas de saúde e programas de atenção integral a famílias. $\mathrm{O}$ atendimento pode ocorrer, de acordo com os autores, no formato sentinela, detectando a 
violência, identificando os maus-tratos e atuando sobre a prevenção. Esses autores também ressaltam a concomitância entre violência conjugal e prática parental e, justamente por isso, defendem a capacitação dos profissionais que atuam junto à família para que tenham uma abordagem mais ampliada, acolhedora e que facilite a revelação e o enfrentamento precoce das situações de violência.

\section{A rede de proteção à criança e ao adolescente na prevenção e enfrentamento da violência}

O Estatuto da Criança e do adolescente (BRASIL, 1990) estabeleceu os direitos da população infanto-juvenil e instituiu que o atendimento à criança e ao adolescente deve se realizar a partir de ações conjuntas e articuladas preconizando intervenções em rede. Nos encontros, foi identificado que apesar de a maioria das participantes já tivessem ouvido falar do ECA, elas desconheciam o seu conteúdo e suas determinações. No entanto, após a entrega de um exemplar do ECA para cada mãe/responsável dos alunos, orientação a respeito de como utilizá-lo e leitura de alguns artigos, foi apontando pelas mesmas a importância de conhecer os direitos da criança e do adolescente e a rede de proteção dos mesmos para prevenir a violência.

Nas oficinas, as discussões a respeito do ECA foram voltadas para o dever do adulto em cuidar e proteger as crianças e adolescentes, bem como, a obrigatoriedade de comunicar aos órgãos competentes as situações de violação de direitos contra a população infantojuvenil. Uma das participantes apontou a preocupação com os netos (possuía a guarda das crianças) e com o bem-estar destes, relatando que quando necessitava se ausentar de casa, sempre deixa os netos aos cuidados de vizinhos e amigos e nunca sozinhos. Outra participante relatou a notificação feita por ela e outros adultos da comunidade ao Conselho Tutelar de uma situação de violência sexual envolvendo uma criança.

Quanto aos órgãos de proteção dos direitos das crianças e dos adolescentes que constituem a rede de proteção, o órgão mais conhecido pelas participantes era o Conselho Tutelar. A maioria das mães/responsáveis já havia solicitado intervenções ou conhecia uma pessoa que já havia solicitado ajuda a este órgão. A partir dos relatos das participantes, podese observar que o Conselho Tutelar era visto, pela maioria das mães/responsáveis, como um órgão de punição aos pais, que retira os filhos, caso necessário. Neste caso, o Conselho Tutelar não era visto como um órgão protetor, mas como uma instituição que retira os filhos de casa e os afasta dos pais. Além disso, as falhas do Conselho Tutelar foram apontadas por algumas participantes, em especial, quando os casos de violência são comunicados e a 
situação de violação permanece, o que parece indicar um certo descrédito quanto a sua função.

O Conselho Tutelar como atuante na esfera municipal é encarregado de zelar pelo cumprimento dos direitos da criança e do adolescente. Este órgão atua em duas frentes de ação: uma preventiva e outra remediativa. A primeira se refere à fiscalização de entidades e a mobilização da comunidade ao exercício de direitos assegurados a todo cidadão. Já a segunda diz respeito à ação diante da violação consumada, defendendo e garantindo a proteção especial preconizada pelo Estatuto da Criança e do Adolescente (BRASIL, 1990).

Além do Conselho Tutelar, durante os encontros, foram expostos outros órgãos e suas funções, dentre eles, o Juizado da Infância e Juventude, a Delegacia de Proteção à Criança e ao Adolescente (DEAM) e o Ministério Público. As participantes também receberam uma Cartilha com o Guia Informativo sobre a rede de proteção do município alvo da ação de extensão (Centro de Referência de Assistência Social - CRAS, Centro de Referência Especializado de Assistência Social - CREAS, Centro de Atenção Psicossocial - CAPS, entre outros). Nesta exposição, foi identificado que as participantes não tinham conhecimento de todos os serviços ofertados pelo município e das atribuições de cada um. Um serviço de atendimento que foi lembrado pelas participantes foi o CAPS infantil devido a encaminhamentos realizados pela instituição escolar.

A rede de proteção à criança e ao adolescente, constituída a partir de ações conjuntas e articuladas no atendimento, é apontada nos estudos científicos como a melhor maneira de enfrentar a violência (FARAJ; SIQUEIRA, 2012; FARAJ; SIQUEIRA; ARPINI, 2016; LOPES et al., 2012). O trabalho em rede se refere ao desenvolvimento de ações coletivas, a partir de relacionamentos, negociações, interesses compatíveis, acordos, movimentos de interação e também de adesão (MOREIRA; MULLER; DA CRUZ, 2012; FARAJ; SIQUEIRA; ARPINI, 2016) para enfrentar a violência. As ações em rede abrangem, entre outros, a recepção e o encaminhamento propriamente dito dos casos, discussão dos casos por todos os profissionais envolvidos no atendimento, acesso aos prontuários e processos judiciais, visitas interinstitucionais (abrigo, fórum, escola, domicilio), troca de saberes e experiências (LORENCINI; FERRARI; GARCIA, 2002; FARAJ; SIQUEIRA; ARPINI, 2016). Neste sentido, praticar a articulação da rede implica agendas em comum de todos os envolvidos, tanto para o desenvolvimento de acordos em relação aos desafios e ações, como para o acompanhamento dos casos e avaliações de fluxos (BRASIL, 2012). 


\section{Considerações Finais}

Ações voltadas à prevenção primária da violência no contexto escolar são importantes e possíveis para a redução das situações de violência contra crianças e adolescentes, evitando assim prejuízos ao desenvolvimento infantil. Assim, por meio do projeto de extensão "Violência contra crianças e adolescentes: trabalhando prevenção primária" foi possível ofertar as mães e responsáveis de alunos matriculados nas séries iniciais de duas escolas um espaço de diálogo, aprendizado e reflexão a partir de situações vivenciadas por estas, suas famílias e comunidade.

A partir da abordagem de temas como desenvolvimento infantil, alternativas a punição física, fatores de risco para a violência, equipamentos e serviços que constituem a rede de proteção social foi possível ofertar informações e provocar reflexões sobre diferentes aspectos envolvidos na violação de direitos e pensar a respeito da proteção à criança e ao adolescente. Ações de extensão podem ser importantes dispositivos para aproximar o conhecimento acadêmicolcientífico da população atendida. As participantes das oficinas relataram vivências de punição e violência física em suas histórias de vida e no seu cotidiano, tornando essa proposta relevante.

Apesar da pouca adesão, as participantes avaliaram como positiva a ação, considerando as oficinas como um espaço de reflexão e esclarecimento quanto aos danos da violência para o desenvolvimento das crianças. Tal fato, além de reafirmar o compromisso da família na proteção da infância, serve como suporte na efetivação de ações de prevenção primária à violência infantil a partir do fortalecimento dos laços familiares. Como limitação do estudo, pode-se considerar a inclusão de apenas duas Instituições Escolares. Estudos que incluíssem mais escolas poderiam contribuir para ampliar a prevenção da violência contra a população infanto-juvenil.

Dessa forma, considera-se importante a criação de espaços como esse nas escolas para a prevenção de novos casos de violência e/ou reincidência. O apoio das referidas escolas significou um importante passo na busca da prevenção da violência, pois possibilitou a aproximação da equipe com as participantes, auxiliando na efetivação da ação proposta. Além disso, serviu para demonstrar o compromisso social da universidade e da escola no combate à violência. Por fim, acredita-se que relatos de experiência, como este, possibilitam que práticas similares sejam multiplicadas em nosso país em prol da erradicação da violência em suas mais diversificadas formas. 


\title{
SCHOOL AS A PLACE FOR PREVENTION OF VIOLENCE: AN EXPERIENCE REPORT
}

\begin{abstract}
This study aimed to report the experience of workshops of prevention of violence carried out with parents and people responsible for students enrolled in initial school years in two schools, in a city of Rio Grande do Sul, during 2013 and 2014. The workshops aimed to enable the dialogue about violence against children and adolescents, in the sense of preventing it. Participants related having experienced physical violence throughout their lives and daily activities, as well as lacking other resources than physical punishment in disciplining. Abuse of alcohol in the families and lack of knowledge of laws of protection concerning the children and adolescents were reported. The meetings built up a moment to reflect about violence and its damages, as concerns the development of the subjects. Activities such as these should be fostered, aiming at the fulfillment of the social role of the school and university, supporting the prevention of violence.
\end{abstract}

Keywords: Violence; prevention; child.

\section{ESCUELA COMO ESPACIO DE PREVENCIÓN DE LA VIOLENCIA: UN INFORME DE EXPERIENCIA}

\section{Resumen}

Este estudio tuvo como objetivo informar sobre la experiencia de los talleres de prevención a la violencia realizados con los padres y responsables por los alumnos matriculados en los primeros grados de dos escuelas de una ciudad de Rio Grande do Sul, en 2013 y 2014. Los talleres tuvieron como meta posibilitar un espacio para el diálogo sobre la violencia contra los niños y adolescentes con el fin de prevenirla. Las participantes reportaron haber experimentado violencia física en sus historias de vida y en su cotidiano, al no tener otro recurso que el castigo físico para disciplinarlas. Se ha reportado también, la presencia de abuso de alcohol en las familias y el desconocimietno de las leyes de protección para los niños y adolescentes. Los encuentros se constituyeron en un momento de reflexión sobre la violencia y los daños de la misma en el desarrollo de los sujetos. Espacios como ese deben ser fomentados, buscándose el cumplimiento del papel social de la escuela y de la universidad como colaboradoras en la prevención a la violencia.

Palabras clave: violencia; prevención; ninõs.

\section{REFERÊNCIAS}

ALTAFIM, E. R. P.; RODRIGUES, O. M. P. R. Práticas educativas maternas no primeiro ano de vida. Journal of Human Growth and Development, n. 3, v. 25, p. 257-262, 2015.

ALTSCHUL, I.; LEE, S. J.; GERSHOFF, E. T. Hugs, not hits: warmth and spanking as predictors of child social competence. Journal of Marriage and Family, n. 3, v. 78, p. 695$714,2016$.

BARROS, N. A.; TUCCI, A. M. Percepções dos Usuários de Crack sobre as suas Relações Familiares na Infância e Adolescência. Psicologia: Teoria e Pesquisa, v. 34, p. 1-10, 2018.

BRASIL. Estatuto da Criança e do Adolescente. Diário Oficial da União. Lei nº 8.069, de 13 de julho de 1990. Brasília, DF, 1990.

Barbarói, Santa Cruz do Sul, n. 57, p.<254-273>, jul./dez. 2020 
. Ministério da Saúde. Secretaria de Atenção à Saúde. A Política do Ministério da Saúde para Atenção Integral a Usuários de Álcool e outras Drogas. 2ª ed. Brasília: Ministério da Saúde, 2004.

. Linha de cuidado para a atenção integral à saúde de crianças, adolescentes e suas famílias em situação de violências: orientação para gestores e profissionais de saúde. Brasília: Ministério da Saúde. Secretaria de Atenção à Saúde. Departamento de Ações Programáticas Estratégicas, 2010.

Conselho Federal de Psicologia. Referências técnicas para prática de psicólogas (os) no centro de referência especializado da assistência social - CREAS. Conselho Federal de Psicologia. Brasília: CFP, 2012.

Decreto $n^{\circ}$ 9.761, de 11 de abril de 2019. Aprova a Política Nacional sobre Drogas. Diário Oficial [da] República Federativa do Brasil, Poder Executivo, Brasília, DF, 11 abr. de 2019, Seção 1 - Extra, p. 7.

CECCONELlO, A. M.; DE ANTONI, C. D.; KOLLER, S. H. Práticas educativas, estilos parentais e abuso físico no contexto familiar. Psicologia em Estudo, n. 8, p. 45-54, 2003.

CEZAR, P. K; ARPINI, D. M. Registros de Notificação Compulsória de Violência Envolvendo Crianças e Adolescentes. Psicologia: Ciência e Profissão, n. 2, v. 37, p. 432-445, 2017.

D'AFONSSECA, S. M.; WILLIAMS, L. C. A. Habilidades maternas de mulheres vítimas de violência doméstica: uma revisão da literatura. Psicologia: Ciência e Profissão, n. 31, v. 2, p. 236-251, 2011.

D’INCAO, M. Â. Mulher e família burguesa. In: DEL PRIORE, M. (Org.). História das mulheres no Brasil. 10 ed. São Paulo: Contexto, p. 187-201, 2015.

DE ANTONI, A. D; KOLLER, S. H. Uma família fisicamente violenta: uma visão pela teoria bioecológica do desenvolvimento humano. Temas em Psicologia, n. 18, v. 1, p. 17-30, 2010.

Perfil da violência em famílias com história de abuso físico. In: HABIGZANG, L. F; KOLLER, S. H. (Orgs.). Violência contra crianças e adolescentes: teoria, pesquisa e prática. Porto Alegre: Artmed, p. 43-53, 2012.

FALEIROS, V. P.; FALEIROS, E. S. Escola que Protege. Enfrentando a violência contra crianças e adolescentes. $2^{a}$ ed. Brasília: Ministério da Educação, Secretaria e Educação Continuada, Alfabetização e Diversidade, 2008.

FARAJ, S. P.; SIQUEIRA, A. C. O atendimento e a rede de proteção da criança e do adolescente vítima de violência sexual na perspectiva dos profissionais do CREAS. Barbarói, n. 37, p. 67-87, 2012.

FARAJ, S. P; SIQUEIRA, A. C.; ARPINI, D. M. Rede de proteção: o olhar de profissionais do sistema de garantia de direitos. Temas em Psicologia, n. 2, v. 24, p. 727-741, 2016. 
FERREIRA, C. L. S.; CÔRTES, M. C. J. W.; GONTIJO, E. D. Promoção dos direitos da criança e prevenção de maus tratos infantis. Ciência \& Saúde Coletiva, n. 11, v. 24, p. 39974008, 2019.

GARBIN, C. A. S. et al. Conhecimento e percepção dos educadores do ensino infantil sobre violência. Revista Ciência Plural, n. 1, v. 2, p. 37-47, 2015.

GOMIDE, P. I. C. (Coord.). Inventário de estilos parentais - IEF: modelo teórico, manual de aplicação, apuração e interpretação. Petrópolis: Vozes, 2006.

HENRIQUES, B. D.; ROCHA, R. L.; REINALDO, A. M. S. Uso de crack e outras drogas por crianças e adolescentes e seu impacto no ambiente familiar: uma revisão integrativa da literatura. Texto Contexto Enfermagem, n. 25, v. 3, p. 1-10, 2016.

HUTZ, C. S. (Org). Situações de risco e vulnerabilidade na infância e na adolescência: aspectos teóricos e estratégias de intervenção. São Paulo: Casa do Psicólogo, 2002.

IPPOLITO, R. (Coord. Técnica). Guia Escolar: método para identificação de sinais de abuso e exploração sexual de crianças e adolescentes. Brasília, Presidência da República, Secretaria do Especial dos Direitos Humanos, 2004.

JAEGER, Fernanda Pires. Violência de gênero intrafamiliar: compreendendo e enfrentando o fenômeno. In: SIQUEIRA, A. C.; JAEGER, F. P.; KRUEL, C. S. (Coords.). Família e violência: conceitos, práticas e reflexões críticas. Curitiba: Juruá, p. 11-30, 2013.

JUSTINO, Y. A. C.; COTONHOTO, L. A.; NASCIMENTO, C. R. R. A perspectiva de mães a respeito das relações parentais diante de um contexto de violência doméstica contra mulher. Pesquisas e práticas psicossociais, n. 12, v. 3, p. 1-20, 2017.

KOLLER, Silvia Helena. Violência doméstica: uma visão ecológica. In: Amencar (Ed.), Violência doméstica. Brasília: UNICEF, 2000.

KOLLER, S. H.; DE ANTONI, C.; CARPENA, M. E. F. Famílias de crianças em situação de vulnerabilidade social. In: BAPTISTA, M. N.; TEODORO, M. L. M. (Orgs.). Psicologia de família: teoria, avaliação e intervenção. Porto Alegre: Artmed, 2012, p. 156-165.

KRUG, E. G. et al. Relatório Mundial sobre violência e Saúde. Geneva: World Health Organization, 2002.

LOPES, M. D. C. et al. Significados atribuídos por profissionais à violência contra crianças e adolescentes: Uma análise dos estudos atuais. Barbarói, n. 36, p. 56-69, 2012.

LORENCINI, B. D. B.; FERRARI, D. C. A.; GARCIA, M. R. C. Conceito de redes. In: FERRARI, D. C. A.; VECINA, T. C. C. (Eds.). O fim do silencio na violência familiar: Teoria e prática. São Paulo: Agora, p. 298-310, 2002.

LYRA, G. F. D.; CONSTANTINO, P.; FERREIRA, A. L. Quando a violência familiar chega até a escola. In: ASSIS, S. G.; CONSTANTINO, P.; AVANCI, J. Q. (Orgs.). Impactos da violência na escola: um diálogo com professores. Rio de janeiro: Ministério da educação/ Editora FIOCRUZ, 2010, pp. 147-175. 
MALTA, D. C.; BERNAL, R. T. I.; TEIXEIRA, B. S. M; SILVA, M. M. A.; FREITAS, M. I. F. Fatores associados a violências contra crianças em serviços sentinela de urgência nas capitais brasileiras. Ciência \& Saúde Coletiva, n. 9, v. 22, 2889-2898, 2017.

MINAYO, M. C. S.; DESLANDES, S. F. A complexidade das relações entre drogas, álcool e violência. Caderno de Saúde Pública, n. 14, v. 1, p. 35-42, 1998.

MOREIRA, E. P.; MULLER, E. L.; DA CRUZ, L. R. Centro de referência especializado da assistência social: Pesquisa-intervenção na rede de proteção à infância e adolescência.

Barbarói, n. 36, p. 70-82, 2012.

MONTEIRO, A. C. S.; FERNANDES, A. T. R. S.; OLIVEIRA, A. B. M.; PEIXOTO, I. V. P.; PAMPLONA, M. C. C. A. Mothers'perspective on violence against children: constructing meanings. Revista Brasileira de Enfermagem, n. 1, v. 71, p. 40-46, 2018.

NARVAZ, M. G.; KOLLER, S. H. Famílias e Patriarcado: da prescrição normativa à subversão criativa. Psicologia \& Sociedade, n. 18, v. 1, p. 49-55, 2006.

OLIVEIRA, E. B.; BITTENCOURT, L. P.; CARMO, A. C. A importância da família na prevenção do uso de drogas entre crianças e adolescente: papel materno. SMAD, n. 4, v. 2, p. 1-16, 2008.

OLIVEIRA, K. L. C.; GOMES, R. Homens e violência conjugal: uma análise de estudos brasileiros. Ciência \& Saúde Coletiva, n. 16, v. 5, p. 2401-2413, 2011.

PELLEGRINI, J. S. et al. Lei da palmada: reflexões e implicações psicojurídicas. Revista Eletrônica do Curso de Direito da UFSM, n. 8, v.1, p. 183-203, 2013.

PEDERSEN, J. R.; GROSSI, P. K. O abuso sexual intrafamiliar e a violência estrutural. In: AZAMBUJA, M. R. F.; FERREIRA, M. H. M. (Eds.). Violência sexual contra crianças e adolescentes. Porto Alegra: Artmed, p.25-34, 2011,

REICHENHEIM, M. E.; DIAS, A. S.; MORAES, C. L. Co-ocorrência de violência conjugal e contra filhos em serviços de saúde. Revista Saúde Pública, n. 40, v.4, p. 595-603, 2006.

REIS, L. M.; UCHIMURA, T. T.; OLIVEIRA, M. L. F. Perfil socioeconômico e demográfico em uma comunidade vulnerável ao uso e abuso de drogas de abuso. Acta Paul Enfermagem, n. 26, v. 3, p. 276-282, 2013.

RISTUM, M. A violência doméstica contra crianças e as implicações da escola. Temas em Psicologia, n. 1, v. 18, p. 231-242, 2010.

SÁ, D. G. F. et al.. Fatores de Risco para Problemas de Saúde Mental na Infância/Adolescência. Psicologia: Teoria e Pesquisa, n. 26, v. 4, p. 643-652, 2010.

SAFFIOTI, Heleieth Iara Bongiovani. Já se mete a colher em briga de marido e mulher. São Paulo em Perspectiva, n. 13, v. 4, p. 82-91, 1999.

Gênero, Patriarcado, Violência. São Paulo: Editora Fundação Perseu Abramo, 2004. 
A mulher na sociedade de classes. $3^{\circ}$ ed. São Paulo: Expressão Popular, 2013.

SANI, A. I.; CUNHA, D. M. M. Práticas educativas parentais em mulheres vítimas e não vítimas de violência conjugal. Psicologia: Teoria e Pesquisa, n. 27, v. 4, p. 429-437, 2011.

SCHENKER, M.; MINAYO, M. C. S. Fatores de risco e de proteção para o uso de drogas na adolescência. Ciência \& Saúde Coletiva, n. 10, v. 3, p. 707-717, 2005.

SCOTT, J. B.; CEZNE, G. O. M. O vínculo afetivo e a prática do advogado familiarista. Revista Brasileira de Direito de Família e Sucessões, n. 26, p. 30-46, 2012.

SILVEIRA, P. S.; SILVA, E. A. Família, sociedade e uso de drogas: prevenção, inclusão social e tratamento familiar. In: RONZANI, T. M. (Org.). Ações integradas sobre drogas: prevenção, abordagens e políticas públicas. Juiz de Fora: Ed. UFJF, p. 207-222, 2013.

SILVEIRA, R. S.; NARDI, H. C.; SPINDLER, G. Articulações entre gênero e raça/cor em situações de violência de gênero. Psicologia \& Sociedade, n. 26, v.2, p. 323-334, 2014.

VIEIRA, L. B. et al. Abuso de álcool e drogas e violência contra as mulheres: denúncias de vividos. Revista Brasileira de Enfermagem, n. 67, v. 3, p. 366-372, 2014.

ZILBERMAN, M. L.; BLUME, S. B. Violência doméstica, abuso de álcool e substâncias psicoativas. Revista Brasileira de Psiquiatria, n. 27, p. 51-55, 2005.

Data de recebimento: $30 / 10 / 2017$

Data de aceite: 11/08/2020

\section{Sobre os autores:}

Suane Pastoriza Faraj é Psicóloga, Doutoranda do Programa de Pós-graduação em Psicologia da Universidade Federal de Santa Maria. Endereço Eletrônico: suanef@yahoo.com.br

Juliano Beck Scott é Psicólogo clínico e Pesquisador, possui Doutorado (2018) e Pós-Doutor (2019) em Psicologia pela Universidade Federal do Rio Grande do Norte. Atualmente atua como pesquisador colaborador na UFRN. Endereço Eletrônico: bs.juliano@gmail.com

Aline Cardoso Siqueira é Docente dos Programas de Pós-graduação em Ciências da Saúde e Psicologia da Universidade Federal de Santa Maria. Pesquisadora de Produtividade do CNPq Nível 2. Endereço Eletrônico: alinecsiq@gmail.com 